\title{
KETANGGUHAN TEGANGAN TARIK SAMBUNGAN LAS DAN FOTO MIKRO DARI MATERIAL ALUMINIUM- MAGNESIUM PADA PESAWAT TANPA AWAK
}

\author{
Ali M. Nainggolan ${ }^{1}$,Ikhwansyah Isranuri ${ }^{2}$, M. Sabri ${ }^{3}$, Bustami Syam ${ }^{4}$, Syahrul Abda ${ }^{5}$ \\ 1,2,3,4,5 Departemen Teknik Mesin Fakultas Teknik Universitas Sumatera Utara \\ Email: n.marthin@yahoo.com
}

\begin{abstract}
ABSTRAK
Pembangunan konstruksi dengan menggunakan logam pada masa sekarang ini banyak melibatkan unsur pengelasan khususnya bidang rancang bangun karena sambungan las merupakan salah satu pembuatan sambungan yang secara teknis memerlukan keterampilan yang tinggi bagi pengelas,. Salah satu faktor yang mempengaruhi ketangguhan material adalah sifat mekanik dari material tersebut. Jika material diberi proses pengelasan, maka akan dapat merubah sifat mekanik dari material tersebut. Untuk mengkaji hal tersebut disusunlah sebuah konsep penelitian yang terdiri dari dua tahapan. Mengukur kekuatan tarik pengelasan pada Aluminium-Magnesium dan pengujian Metalography. Pengujian tarik pada pengelasan oksiasitilen,menggunakan material dari pesawat tanpa awak dimana nilai regangan rata-rata pada ketiga spesimen adalah 4,1333\%,nilai modulus elastisitas rata-rata adalah 16411,15659 MPa.dan pada pengujian metalografi terlihat warna putih keperakan menunjukan aluminium dan butiran berwarna hitam menunjukan magnesium.
\end{abstract}

Kata kunci: Pengelasan oxy-acetylene, pengujian tarik, - metalography, aluminium magnesium

\section{ABSTRACT}

Building konstruksi using metal at the present time involves many elements of welding,especially in the field of building design for welded joints is one of the manufacture of welded joint which.One of the factors that affect material toughness is the mechanical properties of the material. If the material given welding process, it will be able to change the mechanical properties of the material. To look into the matter was composed of a concept study consisted of two phases. measuring the tensely strength of magnesium and aluminium welding on metalography testing, testing on welding oxy-asitilen where the average strain of three specimen is 4,1333\% andmodulus elasticity is 16411,15659 MPa.wshowed that addition of angular hem and magnesium effect the outcome of welds (tensili strength) and where the testing of metalography look silvery white color shows the details of black aluminium of magnesium show

Keywords: oxy-acetylene gas welding, tensile strenght, metalography, aluminium-magnesium

\section{PENDAHULUAN}

Pengembangan teknologi dibidang konstruksi yang semakin maju tidak dapat dipisahkan dari pengelasan karena mempunyai peranan penting dalam rekayasa dan reparasi logam. Pembangunan konstruksi dengan logam pada masa sekarang ini banyak melibatkan unsur pengelasa khususnya bidang rancang bangun karena sambungan las merupakan salah satu pembuatan sambungan yang secara teknis memerlukan keterampilan yang tinggi bagi pengelas agar diperoleh sambungan dengan kualitas baik..

Lingkup penggunaan teknik pengelasan dalam kostruksi sangat luas meliputi perkapalan, jembatan, rangka baja, bejana tekan, sarana transportasi, rel, pipa saluran dan lain sebagainya. Dalam pekerjaan konstruksi, pengelasan bukan tujuan utamanya melainkan sarana untuk mencapai tujuan yang lebih sempurna (baik). 


\section{TINJAUAN PUSTAKA}

Aluminium murni mempunyai sifat lunak dan kurang kuat terhadap gesekan. Berat Jenis Alumunium murni $2643 \mathrm{~kg} / \mathrm{m}^{3}$ sedangkan titik cair aluminium $660^{\circ} \mathrm{C}$. Kekerasan permukaan aluminium murni 17 BHN sedangkan kekuatan tarik maksimum adalah $4,9 \mathrm{~kg} / \mathrm{m}^{2}$. Untuk memperbaiki sifat mekanis aluminium dilakukan dengan memadukan dengan unsur-unsur lain seperti tembaga, silisium, magnesium, mangan, dan nikel. Padauan aluminium ini memiliki beberapa keunggulan misainya Al-Si, Al$\mathrm{Cu}-\mathrm{Si}$ digunakan untuk bagian mesin, $\mathrm{Al}-\mathrm{Cu}-\mathrm{Ni}-\mathrm{Mg}$ dan $\mathrm{Al}-\mathrm{Si}-\mathrm{Cu}-\mathrm{Ni}-\mathrm{Mg}$ digunakan untuk bagian mesin yang tahan panas, sedangkan Al-Mg untuk bagian yang tahan korosi[1].

\section{a. Paduan Aluminium-Magnesium}

Aluminium lebih banyak dipakai sebagai paduan daripada logam paduan sebab tidak kehilangan sifat ringan dan sifat-sifat mekanisnya serta mampu cornya diperbaiki dengan menambah unsur-unsur lain. Unsur-unsur paduan yang tidak ditambahkan pada Aluminium murni selain dapat menambah kekuatan mekaniknya juga dapat memberikan sifat-sifat baik lainnya seperti ketahanan korosi dan ketahanan aus.

Keberadaan Magnesium hingga 15,35\% dapat menurunkan titik lebur logam paduan yang cukup drastis, dari $660^{\circ} \mathrm{C}$ hingga $450^{\circ} \mathrm{C}$. Namun, hal ini tidak menjadikan Aluminium paduan dapat ditempa menggunakan panas dengan mudah karena korosi akan terjadi pada suhu di atas $60^{\circ} \mathrm{C}$. Keberadaan Magnesium juga menjadikan logam paduan dapat bekerja dengan baik pada temperatur yang sangat rendah, di mana kebanyakan logam akan mengalami failure pada temperatur tersebut.

\section{b. Proses Pengecoran}

Proses pengecoran akan dihasilkan Aluminium dengan sifat-sifat yang diinginkan. Aluminium murni memiliki sifat mampu cor dan sifat mekanis yang tidak baik, maka dipergunakanlah Aluminium alloy untuk memperbaiki sifat tersebut. Beberapa elemen alloy yang sering ditambahkan diantaranya Tembaga, Magnesium, Mangan, Nikel, Silikon dan sebagainya [2].

Pada desain coran perlu dipertimbangkan beberapa hal sehingga diperoleh hasil coran yang baik, yaitu bentuk dari pola harus mudah dibuat, cetakan dari coranhendaknya mudah, cetakan tidak menyebabkan cacat pada coran. Untuk membuat cetakan, dibutuhkan saluran turun yang mangalirkan cairan logam kedalam rongga cetakan. Besar dan bentuknya ditentukan oleh ukuran, tebalnya irisan dan macam logam dari coran. Selanjutnya diperlukan penentuan keadaan-keadaan penuangan seperti temperatur penuangan dan laju penuangan.

\section{c. Pengelasan}

Pengelasan (welding) adalah salah salah satu teknik penyambungan logam dengan cara mencairkan sebagian logam induk dan logam pengisi dengan atau tanpa tekanan dan dengan atau tanpa logam penambah dan menghasilkan sambungan yang continu [3]..

Definisi pengelasan menurut DIN (Deutsche Industrie Normen) adalah ikatan metalurgi pada sambungan logam atau logam paduan yang dilaksanakan dalam keadaan lumer atau cair. Dengan kata lain, las adalah sambungan setempat dari beberapa batang logam dengan menggunakan energi panas. Dalam proses penyambungan ini adakalanya disertai dengan tekanan dan material tambahan (filler material). 


\section{d. Las Oxy-Acetilene}

Pengelasan dengan oxy-acetylene adalah proses pengelasan secara manual dengan pemanasan permukaan logam yang akan dilas atau disambung sampai mencair oleh nyala gas acetylene melalui pembakaran $\mathrm{C}_{2} \mathrm{H}_{2}$ dengan gas $\mathrm{O}_{2}$ dengan atau tanpa logam pengisi. Proses penyambungan dapat dilakukan dengan tekanan sangat tinggi sehingga dapat mencairkan logam [4].

Pengelasan dengan gas dilakukan dengan membakar bahan bakar gas yang dicampur dengan oksigen $\left(\mathrm{O}_{2}\right)$ sehingga menimbulkan nyala api dengan suhu tinggi $\left(3000^{\circ} \mathrm{C}\right)$ yang mampu mencairkan logam induk dan logam pengisinya. Jenis bahan bakar gas yang digunakan adalah acetylene, propana atau hidrogen, sehingga cara pengelasan ini dinamakan las oxy-acetylene atau dikenal dengan nama las karbit.

Pengelasan dapat dilakukan dengan atau tanpa logam pengisi. Oksigen diperoleh dari proses elektrolisa atau proses pencairan udara. Oksigen komersil umumnya berasal dari proses pencairan udara dimana oksigen dipisahkan dari nitrogen. Oksigen ini disimpan dalam silinder baja pada tekanan $14 \mathrm{MPa}$. Gas asetilen $\left(\mathrm{C}_{2} \mathrm{H}_{2}\right)$ dihasilkan dari reaksi kalsium karbida dengan air.

\section{e. Kampuh Las}

Untuk menghasilkan kualitas sambungan las yang baik, salah satu faktor yang harus diperhatikan yaitu kampuh las. Kampuh las ini berguna untuk menampung bahan pengisi agar lebih banyak yang merekat pada benda kerja, dengan demikian kekuatan las akan terjamin.

Faktor-faktor yang harus diperhatikan dalam pemilihan jenis kampuh adalah:

1. Ketebalan benda kerja.

2. Jenis benda kerja.

3. Kekuatan yang diinginkan.

4. Posisi pengelasan.

Sebelum memulai proses pengelasan terlebih dahulu ditentukan jenis sambungan las yang akan dipilih. Hal-hal yang harus diperhatikan bahwa sambungan yang dibuat akan mampu menerima beban (beban statis, beban dinamis, atau keduanya).

\section{e. Pengujian Tarik}

Proses pengujian tarik bertujuan untuk mengetahui kekuatan tarik benda uji. Pengujian tarik untuk kekuatan tarik daerah las dimaksudkan untuk mengetahui apakah kekuatan las mempunyai nilai yang sama, lebih rendah atau lebih tinggi dari kelompok raw materials. Pengujian tarik untuk kualitas kekuatan tarik dimaksudkan untuk mengetahui berapa nilai kekuatannya dan dimanakah letak putusnya suatu sambungan las [5]

Pembebanan tarik adalah pembebanan yang diberikan pada benda dengan memberikan gaya tarik berlawanan arah pada salah satu ujung benda. Penarikan gaya terhadap beban akan mengakibatkan terjadinya perubahan bentuk (deformasi) bahan tersebut. Proses terjadinya deformasi pada bahan uji adalah proses pergeseran butiran Kristal logam yang mengakibatkan melemahnya gaya elektromagnetik setiap atom logam hingga terlepas ikatan tersebut oleh penarikan gaya maksimum.

Bila gaya tarik terus diberikan kepada suatu bahan (logam) sampai putus, maka akan didapatkan profil tarikan yang lengkap berupa kurva . Kurva ini menunjukkan hubungan antara gaya tarikan dengan perubahan panjang. Profil ini sangat diperlukan dalam desain yang memakai bahan tersebut [4].

Perubahan panjang dalam kurva disebut sebagai regangan teknik $\left(\varepsilon_{\text {eng }}\right)$, yang didefenisikan sebagai perubahan panjang yang terjadi akibat perubahan static $(\Delta \mathrm{L})$ 
terhadap panjang batang mula-mula $\left(\mathrm{L}_{\mathrm{o}}\right)$. Tegangan yang dihasilkan pada proses ini disebut dengan tegangan teknik $\left(\sigma_{\text {eng }}\right)$, dimana didefenisikan sebagai nilai pembebanan yang terjadi $(\mathrm{F})$ pada suatu luas penampang $\left(\mathrm{A}_{\mathrm{o}}\right)$. Tegangan normal tersebut akibat gaya tarik.

Pada prakteknya nilai hasil pengukuran tegangan pada suatu pengujian tarik pada umumnya merupakan nilai teknik. Regangan akibat gaya tarik yang terjadi, panjang akan menjadi bertambah dan diameter pada spesimen akan menjadi kecil, maka ini akan terjadi deformasi plastis (Nash, 1998)[6].

E adalah gradient kurva dalam daerah liner, dimana perbandingan tegangan $(\sigma)$ dan regangan ( $(\varepsilon)$ selalu tetap. E diberi nama " Modulus Elastisitas " atau "Young Modulus ". Kurva ini ditunjukkan oleh gambar 1.

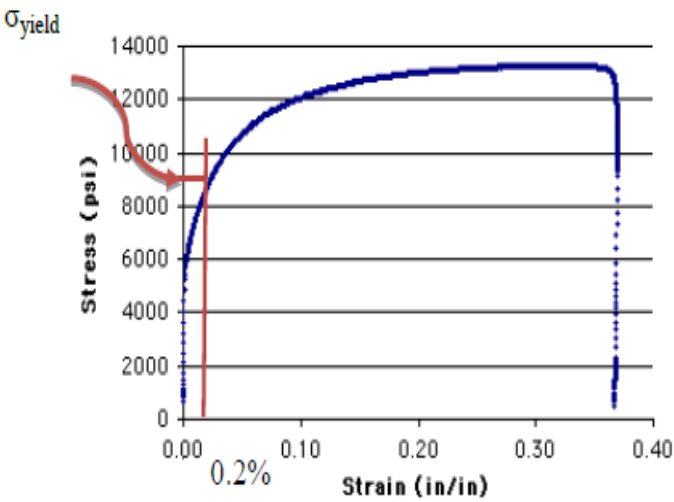

gambar 1 kurva tegangan -regangan [6].

\section{f. Foto Mikro}

Struktur bahan dalam orde kecil sering disebut struktur mikro. Struktur ini dapat dilihat dengan mata telanjang, tetapi harus menggunakan alat pengamat struktur mikro. Penelitian ini menggunakan mikroskop cahaya. Persiapan yang dilakukan sebelum mengamati struktur mikro adalah pemotongan spesimen, pengampelasan, pemolesan, dan pengetsaan. Setelah dipilih, bahan uji diratakan permukaannya dengan menggunakan kikir. Setelah rata digosok dengan menggunakan ampelas mulai dari yang kasar sampai yang halus.

Arah pengampelasan tiap tahap harus diubah, pengampelasan yang lama dan penuh kecermatan akan menghasilkan permukaan yang halus dan rata. Bahan yang halus dan rata diberi autosol untuk membersihkan noda yang menempel pada bahan. Langkah terakhir sebelum dilihat struktur mikro adalah dengan mencelupkan specimen kedalam larutan etsa dengan penjepit tahan karat dan permukaan menghadap keatas. Kemudian specimen dicuci, dikeringkan dan dilihat struktur mikronya.

\section{METODE PENELITIAN}

Penelitian ini dilakukan untuk mengetahui nilai modulus elastisitas,tegangan dan regangan dari masing-masing spesimen setelah dilakukan proses pengelasan dan untuk mengetahui struktur mikro dari material tersebut.

\section{Bahan Dan Alat Penelitian}

Bahan yang dipergunakan dalam penelitian ini adalah paduan AluminiumMagnesium dari body pesawat tanpa awak yaitu dalam bentuk spesimen sesuai standart ASME E8. 
Adapun peralatan yang dipergunakan selama penelitian ini adalah :

1. Gergaji (saw).

2. Gerinda Tangan.

3. Mesin Las

4. Mesin Sekrap

5. Alat Uji Tarik

2. Prosedur Penelitian

a. Prosedur Pengujian Tarik

Adapun prosedur yang dilakukan pada pengujian tarik (tensile test) adalah :

a. Dipersiapkan spesimen untuk uji tarik (tensile test) sesuai dengan standar ASME E8.

b. Alat uji tarik yang digunakan adalah alat uji tarik Torsee Type AMU-10 Pasanglah spesimen dengan hati-hati pada grip mesin uji tarik,catat lah setiap langkah-langkah operasional setting pengujian dengan seksama.

c. Mulai lah penarikan dan perhatikan dengan baik mekanisme deformasi yang terjadi pada benda uji serta tampilan grafik, beban perpanjangan yang terlihat pada recorder,teruskan pengamatan hingga terjadi beban maksimum dan dilanjutkan dengan nacking atau perpatahan.

d. Tandailah pada grafik beban perpanjangan titik-titik terjadinya beban maksimum dan perpatahan.

e. Lepaskan spesimen dari grip mesin uji tarik,satukan kembali benda uji dan ukur panjang akhir(L)

f. Catat hasil pengukuran di dalam lembar data.

3. Prosedur Pengujian Metallography

Untuk mengetahui sturuktur mikro dari suatu logam pada umumnya dilakukan dengan reflek pemendaran(sinar), maka pada pengujian metalography ini, terlebih dahulu benda uji di potong kemudian diratakan permukaan yang akan dilihat struktur mikronya.Setelah proses perataan pada spesimen, kemudian proses pengamplasan dengan kertas pasir ukuran 120, 240, 400, 600, 800, 1000, 1200, dan 1500 .

Kemudian sampel dipoles dengan kain panel, air dan aluminium dioksida (bubuk alumina) untuk didapat permukaan seperti cermin, kemudian sampel dietsa

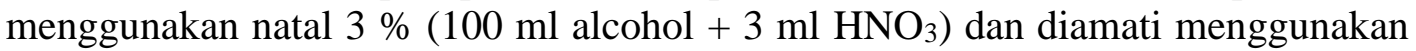
mikroskop optik agar didapat bentuk mikrostrukturnya serta diameter butir sesuai metode planimetri.

\section{HASIL DAN ANALISA}

Paduan Aluminium-Magnesium (Al-Mg) yang dipadukan memiliki perbandingan Aluminium 96\% dan Magnesium 4\%. Jumlah perbandingan paduan tersebut merupakan perbandingan paduan yang ideal untuk digunakan sebagai material sayap pesawat tanpa awak. Selain itu untuk mengetahui sifat mekanisnya dilakukan pengujian sebagai berikut:

1. Pengujian Tarik (Tensile strength)

2. Pengujian Metallography.

\section{Pengujian Tarik}

Pada penelitian ini pengujian tarik menggunakan alat uji tarik Torsee TypeAMU10dengan standar uji tarik Annual book ASTM Vol.3 E8M-00b. Pengujian ini dilakukan agar mengetahui bagaimana bahan tersebut bereaksi terhadap energi tarikan 
dan sejauh mana material itu bertambah panjang.Hasil dari uji tarik dapat dilihat pada gambar dibawah ini;

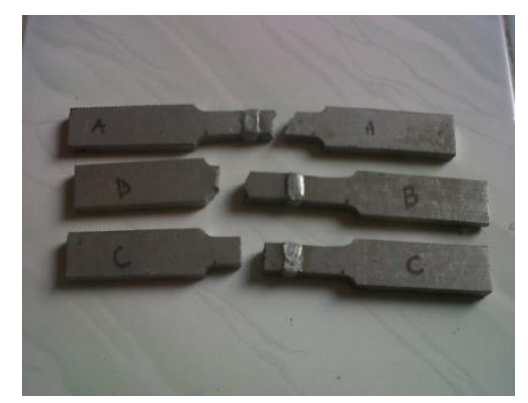

Gambar 2 Spesimen setelah diuji tarik.

Dari gambar diatas terlihat daerah patahan pada spesimen yang berbeda beda dan menunjukkam bahwa sambungan lasan nya lebih kuat. dd

Berikut adalah gambar dari kurva dan hasil pengujian tarik: 1.Spesimen I

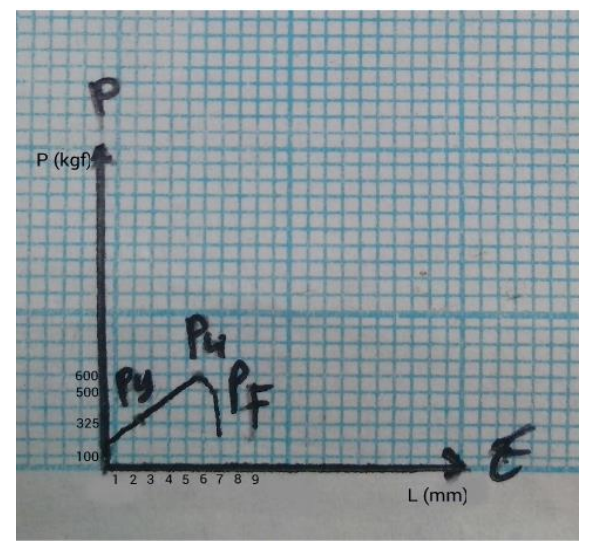

Gambar 3 kurva hasil uji tarik spesimen I.

Dari kurva pengujian tarik Spesimen I Terlihat beban Ultimate (Pu) mempunyai nilai $600 \mathrm{kgf}$,beban fracture (pf) mempuinyai nilai $500 \mathrm{kgf}$, dan beban yield (py) mempunyai nilai $325 \mathrm{kgf}$ seperti terlihat pada gambar 3 diatas.

2. Spesimen II.

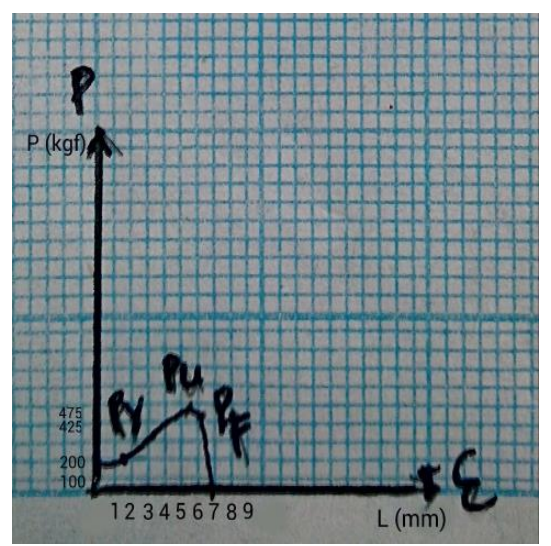

Gambar 4 kurva hasil uji tarik spesimen II.

Dari kurva pengujian tarik spesimen II , terlihat beban ultimate $(\mathrm{Pu})$ mempunyai $475 \mathrm{kgf}$, beban fracture ( Pf ) mempunyai nilai $425 \mathrm{kgf}$, dan beban yield (Py) mempunyai nilai $200 \mathrm{kgf}$ seperti terlihat pada gambar 4 diatas. 
3. Spesimen III.

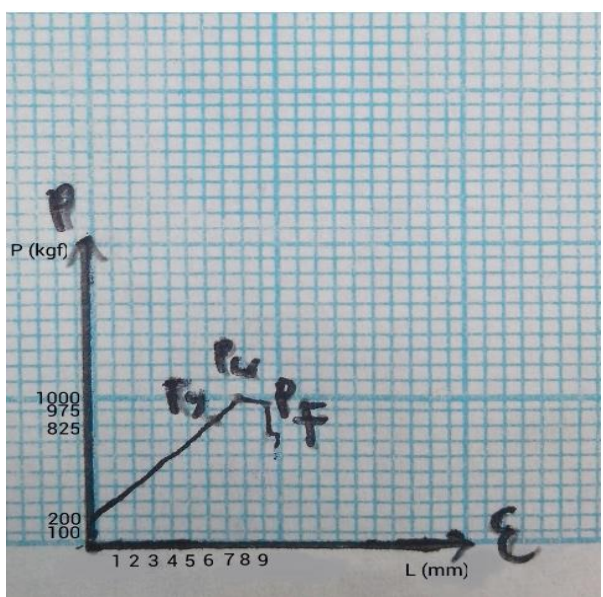

Gambar 5 kurva hasil ujitarik spesimen III.

Dari kurva pengujian tarikspesimen III A196\%-Mg4\% terlihat beban ultimate $(\mathrm{Pu})$ mempunyai nilai $1000 \mathrm{kgf}$, beban fracture (Pf) mempunyai nilai975 kgf, dan beban yield (Py) $825 \mathrm{kgf}$ saperti pada gambar 5 diatas.

Berikut ini adalah hasil pengujian dan tabel hasil pengujian untuk regangan dan modulus elastisitas dari hasil uji kekuatan tarik maka dilakukan perhitungan sebagai berikut;

a. Regangan $(\varepsilon)$

Untuk nilai regangan diambil nilai perpanjangan setiap spesimen uji. Maka nilai regangan dapat ditentukan dari persamaan berikut :

Nilai regangan untuk masing-masing spesimen. Untuk Spesimen 1sebesar 3,90 $\%$, Spesimen 2 sebesar 3,59\%, Spesimen 3 sebesar 4,85\%.

Nilai regangan dapat dilihat pada tabel 1

\begin{tabular}{|c|c|c|c|}
\hline Kadar & Spes & $\varepsilon(\%)$ & $\varepsilon($ ratarata $)$ \\
\hline \multirow{2}{*}{$\begin{array}{c}\mathrm{Al} \\
96 \%\end{array}$} & 1 & 3,90 & \multirow{3}{*}{4,11333} \\
\hline & 2 & 3,59 & \\
\hline $\begin{array}{l}\mathrm{Mg} \\
4 \%\end{array}$ & 3 & 4,85 & \\
\hline
\end{tabular}

b. Modulus elastisitas (E)

Dari persamaan diperoleh nilai modulus Elastisitas dari masing-masing spesimen. Untuk spesimen 1 sebesar 15384,61 MPa, spesimen 2 sebesar 13231,19 MPa, Spesimen 3 sebesar 20618,55 MPa.

b. Hasil Pengujian Metallography

Sifat-sifat logam terutama sifat mekanis dan sifat teknologis sangat mempengaruhi oleh mikro struktur logam dan paduannya. Struktur mikro dari logam dapat diubah dengan jalan perlakuan panas ataupun dengan proses perubahan bentuk (deformasi) dari logam yang akan diuji. Pengamatan metallography dengan mikroskop optik dapat dibagi dua, yaitu metallography makro yaitu pengamatan struktur dengan perbesaran 10-100 kali dan metallography mikro yaitu pengamatan struktur dengan perbesaran diatas 100 kali.

Pengujian mikrostruktur dilakukan dengan menggunakan Reflected Metallurgical Microscope dengan type Rax Vision No. 545491, MM-10A,230V-50Hz. 
Analisa struktur mikro kita dapat mengamati bentuk dan ukuran kristal logam, kerusakan logam akibat proses deformasi, proses perlakuan panas, dan perbedaan komposisi.

Hasil foto mikro dari spesimen dapat dilihat pada gambar berikut :

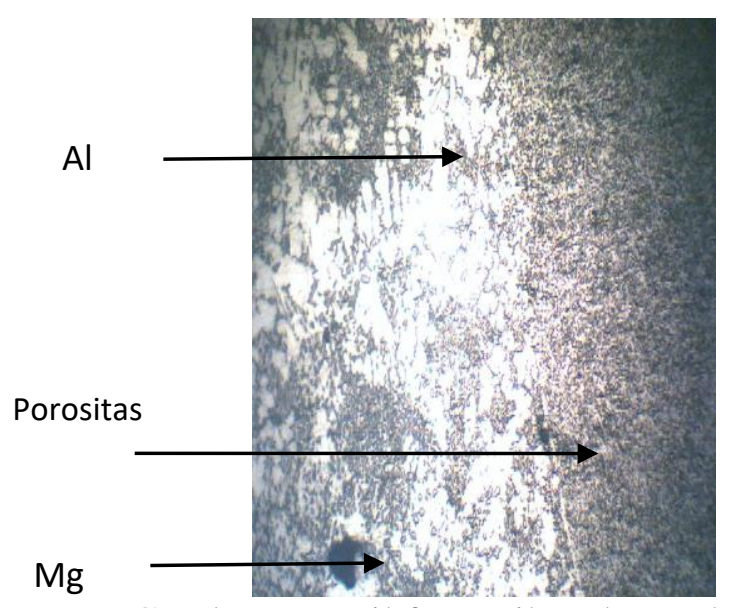

Gambar 6 Hasil foto mikro batas daerah lasan paduan AL-Mg dengan pembesaran 200x.

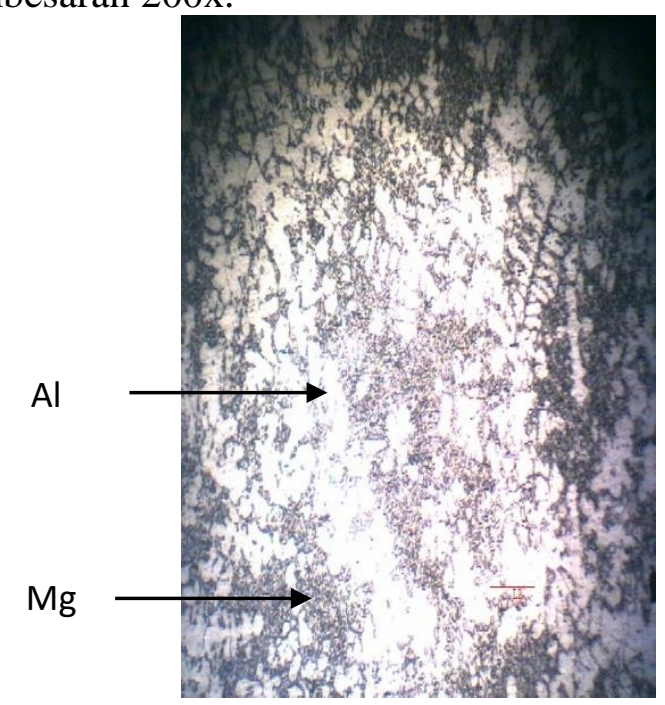

Gambar 4.8 Hasil photo mikro Lasan Dengan Perbesaran 200 x.

Gambar diatas memperlihatkan hasil foto daerah lasan dengan perbesaran 200 $\mathrm{x}$, dimana permukaan Aluminium terlihat lebih terang setelah mengalami penambahan kadar Magnesium yang artinya perpaduan yang terjadi secara merata dan sempurna.

\section{KESIMPULAN}

Dari hasil penelitian yang telah dilakukan pada pengelasan oksi-asitilen pada paduan aluminum-magnesium,dapat diperoleh beberapa kesimpulan yang merupakan jawaban dari tujuan penelitian ini. Hasi-hasil penelitian tersebut dapat ditarik kesimpulan sebagai berikut:

1. Variasi waktu pengelasan berpengaruh terhadap gaya geser maksimum hasil pengelasan sedangkan Variasi ketebalan material berpengaruh terhadap waktu pengelasan

2. Dari hasil pengujian bahwa pada pengelasan oksi-asitilen untuk paduan aluminium 96\% magnesium4\%, bahwa kandungan magnesium,besar sudut kampuh,mempengaruhi hasil lasan (kekuatan tarik). 
3. Dari hasil photo mikro dilihat bahwa adanya pengaruh suhu nyala api las oksiasitilen terhadap aluminium-magnesium.

\section{DAFTAR PUSTAKA}

[1] ASM Handbook.1988. Metal handbooksninth Edition Volume 15 Casting. The University of Alabama.

[2] ASM Handbook.2000.Volume 9 Metallography and Microstructures. Intenational ASM.

[3] Harsono Wiryosumatro \& Thoise Okumura, Teknologi Pengelaan Logam. Pradya Paramita, Jakarta Cetakan ke IX.

[4] S, Widharto,2007. Menuju Juru Las Tingkat Dunia, cetakan pertama, Jakarta, Pradnya pramita

[5] Sindo kou. WELDING METALLURGY.University of Wiconsin

[6] Surdia, Tata\& Chijiiwa Kenji.1991.TEknik Pengecoran Logam. Jakarta : Pradnya Paramita. 